\title{
SECTOR EXTERNO, CRECIMIENTO ECONÓMICO Y BIENESTAR EN BAJA CALIFORNIA: 1970-1988
}

\author{
Por \\ Jorge García Montaño*
}

\begin{abstract}
RESUMEN
El presente trabajo tiene el objetivo de presentar los efectos del desarrollo del sector extemo de Baja California en el crecimiento de la economía local y en relación con algunos indicadores del bienestar social. También se estudian algunos indicadores nacionales comparativos entre la entidad y los promedios nacionales, tal que permitan ubicar las especificidades del desarrollo de Baja California. El trabajo se divide en varios apartados: ciclos económicos, comportamiento del sector externo y sus relaciones con el producto interno bruto y la inflación. Todas estas variables interactúan en este estudio macroeconómico regional.

La conclusión, hace referencia a que en Baja California el sector externo cumple un papel determinante para el crecimiento económico y el bienestar social; por lo tanto, cualquier trastorno negativo en sus variables desagregadas impacta inmediatamente las tasas de crecimiento y los niveles de vida de la población bajacaliforniana, fundamentalmente los cambios extraordinarios del tipo de cambio peso-dólar y los ajustes de las políticas en comercio exterior. De ahí la actualidad del estudio, dado que el Tratado de Libre Comercio de México con Estados Unidos y Canadá tendrá, seguramente, importantes impactos en la entidad.
\end{abstract}

\begin{abstract}
This work studies the effects of Baja California extemal sector development on the growth of the local economy and also in relation with some social well-being indicators. Also, some national comparative indicators are studied between the state and the national mean, so that they allow to establish the specificities of Baja California development.

The work is divided in several parts: economic cycles, external sector behavior, and its relation with gross internal product and inflation. All these variables interact in this regional macroeconomic study.

The conclusion refers to the fact that, in Baja California, the external sector plays a determinant role for the economic growth and the social well-being: thus, every negative change in its desaggregate variables, fundamentally the extraordinary changes in the exchange rate dollar-peso and the adjustments of foreign trade policies, hits immediately the growth rates and the life standards of Baja California population.

So the importance of this study, since the Mexico's Free Trade Agreement with USA and Canada will have, no doubt of it, a strong impact in the state.
\end{abstract}

* Lic. en sociología y Mtro. en economía. Realiz6 su doctorado en estudios de población en El Colegio de México. Actualmente es investigador en el Centro de Estudios para el Desarrollo de la Administración Municipal (CRDAM). 


\section{INTRODUCCIÓN}

El presente trabajo tiene el objetivo de estudiar los efectos del sector externo en el crecimiento económico y en el bienestar social de la población de Baja California.

Operativamente, se entiende por crecimiento económico el comportamiento del producto interno bruto (PIB); asimismo, en este trabajo se entiende como un indicador de bienestar social al comportamiento del ingreso per cápita (IPC: cociente entre PIB y la población total). Estos dos indicadores se analizan durante los años de 1970 a 1988.

En la primera parte se estudian los ciclos de las economías de México y Baja California con el fin de ubicar el comportamiento de esta última respecto a la nacional; se resaltan también las características de la economía fronteriza en cuanto a las implicaciones que tiene esta región para el crecimiento de la entidad.

La idea básica en la primera parte del trabajo es que existe una diferencia entre los comportamientos económicos de México y Baja California (B. C.). Esta diferencia resalta en los años de fuertes devaluaciones: la economía de B. C. sufre un impacto negativo mayor que en el resto del país. Dicha situación afecta relativamente más al indicador del ingreso per cápita de la entidad que a nivel nacional; aunque en términos absolutos el ingreso per cápita sigue siendo mayor en B. C. que el nacional.

Posteriormente, en la segunda parte, se analizan las balanzas comerciales de México y Baja California, con el objetivo de ponderar adecuadamente la importancia de éstas en el desempeño económico. La dinámica del sector externo se evalúa por medio de los "per cápita del sector externo" (cociente de los valores de las variables de este sector entre la población).

No sorprende que se compruebe que las importaciones para la entidad son más importantes para la población de B. C. que para México; además, el comportamiento de los indicadores "per cápita del sector externo" de B. C. muestran un movimiento notablemente más sensible a las políticas económicas —como son las devaluaciones- que en el resto del país.

En la última parte del trabajo presentamos los resultados de un análisis de regresión lineal múltiple para evaluar la importancia que tiene el comercio exterior en el PIB y en el ingreso per cápita (IPC) para Baja California. Se llega a la conclusión de que el comercio exterior en la entidad tiene una mayor importancia para el valor del ingreso per cápita que para el crecimiento del PIB. La variable que más influye positivamente en el ingreso per cápita de Baja California resulta ser los egresos en las transacciones fronterizas, y en términos negativos las exportaciones. Además, se puede afirmar que Baja California tiene un crecimiento económico, 
desde 1982, con una dinámica constante en el deterioro del bienestar de la población; es decir, mientras que el PIB tiene tasas de crecimiento positivas, las tasas en el IPC son negativas: el sector externo tiene un papel fundamental en la configuración contradictoria de este proceso: un crecimiento económico paralelo a un deterioro en el bienestar social.

\section{LOS CICLOS ECONÓMICOS}

México inicia sus ciclos económicos modernos desde 1940. La primera fase de crecimiento industrial se encuentra entre los años de 1940 a 1954. Una segunda fase va de 1955 a 1961; fase típicamente de transición, donde se operan importantes cambios en el aparato industrial así como en el sector agrícola. Es en estos años donde se inició un proceso de producción de bienes duraderos, fuertes importaciones de bienes de capital, consolidación del mercado interno y fortalecimiento económico del estado mexicano.

A partir de 1962 se observó una pequefia recesión, que pronto fue superada, en 1970. En esta fase, la economía penetró a la era de los monopolios, con una fuerte presencia de empresas transnacionales. Es en 1972 cuando se inició lo que Cordera y Ruiz llaman la "crisis estructural" que dura hasta hoy $(1980,16-17)$.

Este trabajo analiza algunos aspectos de la fase de la crisis estructural que se inaugura en $1972 .{ }^{1}$ Durante estos años, México ha vivido un ciclo económico ${ }^{2}$ caracterizado por fuertes cambios en el sistema productivo, de precios y en sus relaciones económicas con el exterior. Baste imaginar los efectos que el volumen de la deuda externa tiene sobre México. Casi un $50 \%$ de los egresos públicos se dedican actualmente a pagar el pasivo y los intereses de esa deuda externa.

Desde el inicio de la década de los setenta, México vive una dinámica donde los ciclos son más recurrentes y cortos dentro de una fase de "crisis

\footnotetext{
1 Hablamos de "crisis estructural" de una manera diferente al concepto de crisis. Crisis estructural hace referencia a un desajuste prolongado en los indicadores de inversión y consumo, lo cual conlleva inestabilidad crónica en el sistema de precios de los factores de producción y a constantes ajustes en el tipo de cambio de la moneda nacional. En cambio, la palabra "crisis" hace referencia a un momento específico - que puede ser en meses o en un año- donde la tasa de crecimiento del PIB es negativo o constante, es decir, momentos éconómicos donde no existe crecimiento.

2 El ciclo económico contempla varias etapas de una economía mercantil-capitalista, medidas casi siempre por la tasa de crecimiento del producto intemo bruto y por años. Son cuatro etapas básicamente: crisis (crecimiento negativo del PIB), depresión (estancamiento del crecimiento), reanimación (transición de una etapa de crisis y depresión a una de crecimiento) y auge (incremento cunstante en el crecimiento del PIB).
} 
estructural" de largo plazo. La consecuencia "es una reducción de los ritmos de crecimiento o, si se quiere, la tendencia a un estancamiento relativo" (Valenzuela, 1986:34).

En este contexto - como se verá empíricamente en la segunda parte del presente trabajo-; el comercio exterior coadyuva a la dinámica de la crisis estructural, respondiendo a los ciclos económicos en el sentido de que cuando el país se encuentra en años recesivos, o en crisis, las exportaciones aumentan; en cambio, cuando las actividades económicas se recuperan, o están en auge, las importaciones aumentan (Calzada, 1986: 150).

En términos generales, las condiciones del crecimiento económico de México lo hacen vulnerable a los factores externos, en particular a dos hechos: al tipo de cambio y al ciclo cconómico de los Estados Unidos. El patrón económico de México se encuentra ligado al exterior debido al fuerte financiamiento que requiere del exterior y a los altos volúmenes de importación que necesita para funcionar. Esta situación es explicada, en gran parte, por la falta de una integración industrial adecuada, es decir, México no posee una estructura industrial y tecnológica productora de bienes de capital. Un buen porcentaje de éstos son importados; de aquí la importancia de la balanza comercial con el exterior, ya que sin suficientes bienes de capital difícilmente se puede imaginar un crecimiento económico adecuado.

Las importaciones mayores que las exportaciones, los créditos externos y la salida constante de capitales del país al extranjero son las razones objetivas del creciente deterioro de la balanza de pagos que México ha vivido en los últimos años.

En cl cuadro 1 presentamos las estimaciones de la población total y del PIB para México y Baja California. En el cuadro 1.1 se exponen los ciclos económicos según el índice de crecimiento anual del PIB, con el fin de ubicar la dinámica de crecimiento de las economías de México y de B. C. En la figura 1 se presentan los porcentajes anuales de crecimiento del PIB para México y Baja California.

En el análisis del PIB se puede observar que entre los años 1971 y 1976 asistimos al "desarrollo estabilizador", cuyas principales características fueron: una tasa de crecimiento media de 6.17 para México y $5.48 \%$ para B. C., aunque con una varianza ${ }^{3}$ mayor para B. C. que para México. Baja California logró un máximo de 9.18 y México de $8.49 \%$, pero la entidad sí paso por una crisis, la de 1976, donde el PIB decreció por primera vez en muchos años, situación que no se presentó tan profundamente en el país.

3 Hemos seleccionado la varianza como indicador debido a que refleja con mayor claridad la dispersión de los valores anuales que la desviación estándar. 


\section{CUADRO 1. Población total y producto interno bruto de México y Baja California 1970 a 1988.}

\begin{tabular}{|c|c|c|c|c|c|c|}
\hline \multicolumn{3}{|c|}{ Poblaciones a mitad de año } & \multicolumn{2}{|c|}{$\begin{array}{l}\text { Millones de pesos } \\
\text { constantes de } 1970\end{array}$} & \multicolumn{2}{|c|}{$\begin{array}{l}\text { Porcentaje de } \\
\text { crecimiento anual }\end{array}$} \\
\hline Años & México & B. C. & PIB Méx. & PIB B.C. & México & B. C. \\
\hline 1970 & 52217940 & 889825 & 444271 & 11118 & & \\
\hline 1971 & 54032280 & 920856 & 462804 & 11973 & 4.17 & 7.69 \\
\hline 1972 & 55909661 & 953134 & 502086 & 12048 & 8.49 & 0.62 \\
\hline 1973 & 57852272 & 986713 & 544307 & 13006 & 8.41 & 7.95 \\
\hline 1974 & 59862380 & 1021651 & 577568 & 14099 & 6.11 & 8.41 \\
\hline 1975 & 61942330 & 1058008 & 609976 & 15394 & 5.61 & 9.18 \\
\hline 1976 & 63413342 & 1095848 & 635831 & 15244 & 4.24 & -0.97 \\
\hline 1977 & 64919287 & 1135236 & 657722 & 16284 & 3.44 & 6.82 \\
\hline 1978 & 66460996 & 1176241 & 711983 & 17781 & 8.25 & 9.19 \\
\hline 1979 & 68039317 & 1218938 & 777163 & 18951 & 9.15 & 6.58 \\
\hline 1980 & 69655120 & 1263400 & 841855 & 20119 & 8.32 & 6.16 \\
\hline 1981 & 71350152 & 1306140 & 908765 & 21326 & 7.95 & 6.00 \\
\hline 1982 & 73019520 & 1350578 & 903839 & 21219 & -0.54 & -0.50 \\
\hline 1983 & 74669936 & 1396785 & 856174 & 20635 & -5.27 & -2.75 \\
\hline 1984 & 76307608 & 1444840 & 887647 & 21047 & 3.68 & 2.00 \\
\hline 1985 & 77938288 & 1494823 & 912334 & 21363 & 2.78 & 1.50 \\
\hline 1986 & 79567248 & 1542776 & 897812 & 21897 & -1.59 & 2.50 \\
\hline 1987 & 81199248 & 1592686 & 895865 & 22453 & -0.22 & 2.54 \\
\hline 1988 & 82838592 & 1644639 & 905745 & 23008 & 1.10 & 2.47 \\
\hline
\end{tabular}

Fuente: IX Censo de Población de 1970. Para México: "Proyecciones de la población de México y entidades federativas: 1980-2010." INEGI y CONAPO. México, 1985. Para Baja Califomia: 1980, estimaciones de CONAPO-CONEPO, 1985. La población de 1971 a 1979 se interpoló en base a la tasa geométrica intercensal por edades, donde $\mathrm{r}$ general $=3.56$. Para 1986 nos basamos en la Encuesta Demográfica de Baja California 1986. (ED-BC) de CONEPO, p. 151 y se estimó a mitad de año. Para 1987 estimaciones de la misma: CONEPO-BC, CRIM-UNAM. Encuesta Continua de Baja California de 1987. ns-uABC, Mexicali, B. C. 1988. Posteriormente se ajustaron esas poblaciones, según el siguiente método: primero se estimaron a mitad de año. Posteriormente las tasas geométricas por edad se ajustaron de mayor a menor, suponiendo una disminución suave de esas tasas por grupos de edad. Así, la tasa general de 1980 a 1985 fue de 3.36 y para 1985 a 1990 de $3.16 \%$. Las diferencias con la población de la encuesta mencionada son las siguientes: la ED-BC de 1986 subregistró 19,300 habitantes, y sobreregistra 80,774 habitantes en 1987 . según nuestro método.

Para el PIB: para México: SPP, INEGI: "SCNM, 1960-1985" (NAFINSA/88. pp. 80-81). Para B. C.: 1970,1975 y de 1980 a 1987 , estimaciones del LAP-BC: "PMD-Mexicali". (Plan Municipal de Desarrollo de Mexicali). Para 1988, estimaciones del LAP-BC. Para los demás años: LAP-BC: documento interno, y estimaciones del autor. Para los años 1988: "Avances de información económica. PIB trimestral." INEGL. Junio de 1989. 
CUADRO 1.1. PIB de México y de Baja California a precios constantes.

Estadística por ciclo económico según el índice de crecimiento

\begin{tabular}{lccccc} 
Categoría & Años & Media & Varianza & Máximo & Mínimo \\
\hline \multirow{2}{*}{ PIB México: } & $1970-1976$ & 6.17 & 3.07 & 8.49 & 4.17 \\
& $1977-1981$ & 7.42 & 4.12 & 9.15 & 3.44 \\
& $1982-1988$ & -0.01 & 7.59 & 3.68 & -5.27 \\
PIB B. C. & & & & & \\
& $1970-1976$ & 5.48 & 16.41 & 9.18 & -0.97 \\
& $1977-1981$ & 6.95 & 1.34 & 9.19 & 6.00 \\
& $1982-1988$ & 1.11 & 3.47 & 2.54 & -2.75
\end{tabular}

FUENTE: Cuadro 1.

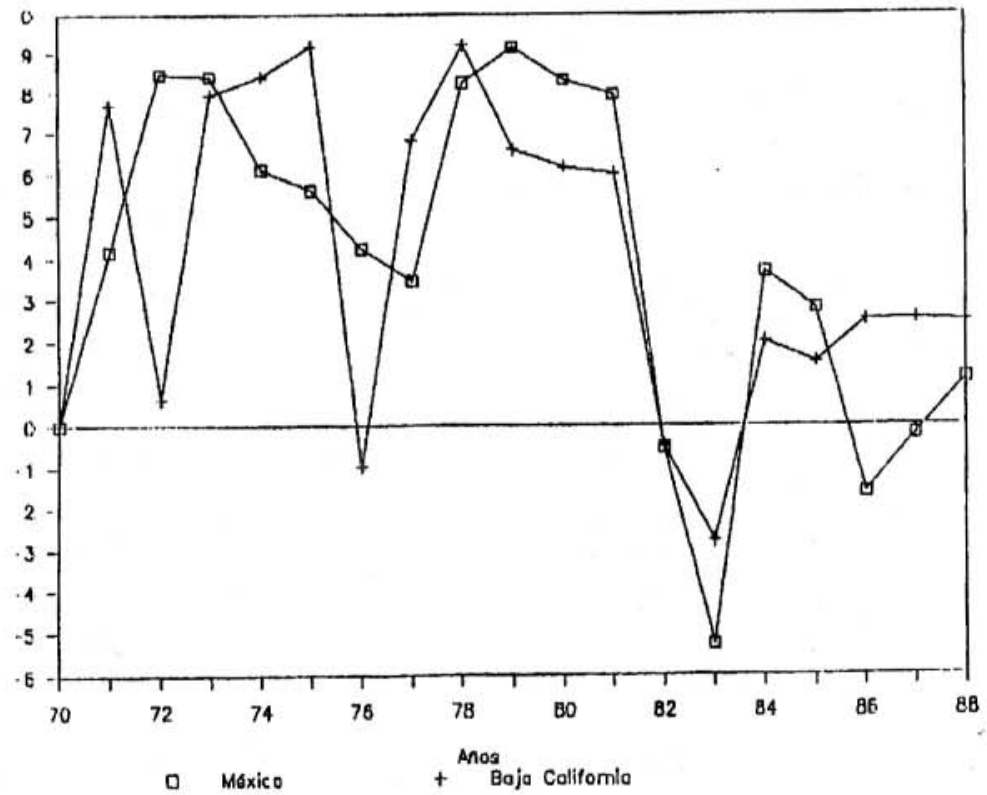

FIGURA 1. PIB: México-Baja California. Porcentaje de crecimiento anual. 
En la fase del "auge petrolero", 4 de 1977 a 1981, existe un crecimiento impresionante: una media de 7.42 para México y $6.95 \%$ para B. C., pero ahora con una varianza mayor en el PIB nacional. En estos pocos años no se experimentó crecimiento negativo; el mínimo para el país fue de 3.44 y para B. C. de $6.0 \%$. Probablemente el crecimiento de México fue más fuerte, pero menos estable que el de B. C. Este auge terminó en 1982.

De 1982 a 1988 la situación del país entró en una fase de transición crítica. En estos años se sepultó definitivamente el modelo de crecimiento que se había instaurado desde 1940. México entra en un proceso de fuertes cambios, caracterizados por la búsqueda de un modelo de crecimiento que, en términos generales, puede ser llamado "modelo secundario exportador" cuyos rasgos esenciales los sintetiza Valenzuela (1986:166) en los siguientes puntos: "a) énfasis en las ramas industriales más pesadas, de bienes intermedios y de capital, en las cuales se daría un avance importante respecto a su actual nivel de sustitución de importaciones; b) caída del salario real, aumento del desempleo abierto y del grado de monopolio. En suma, redistribución regresiva del ingreso; c) gran apertura externa y fuerte expansión de las exportaciones manufactureras".

Observando el cuadro 1.1 se aprecia que el índice de crecimiento medio para México durante los años de 1982 a 1988 fue de $-0.01 \%$, es decir, nos encontramos verdaderamente frente a una situación de estancamiento económico, con un máximo de 3.68 y un mínimo de $-5.27 \%$. En cambio para B.C. el panorama es algo diferente para estos últimos años: una media de 1.11 , con un máximo de 2.54 y un mínimo de -2.75 ; lo cual denota un ritmo de crecimiento económico diferenciado para cada una de las unidades: la entidad no se encuentra en crisis, sino en años de recuperación y crecimiento.

Ahora bien, analicemos la segunda variable de interés para este estudio: los niveles de bienestar. El indicador que seleccionamos para el caso es el ingreso per cápita (IPC) cuyos valores exponemos en el cuadro 2 , y en la figura 2 sus porcentajes de crecimiento anual.

\footnotetext{
4 "Como resultado de los poderosos estímulos que derivaban del Plan Nacional de Desarrollo Industrial, la acumulación de capital experimentó un verdadero salto en 1978. La formación bruta de capital fijo crecí en una tasa cuatro veces superior a la de 1977 , o sea a un $18 \%$ real, en tanto que el PIB lo hizo en un $8.2 \%$. El extraordinario crecimiento de la inversión privada que acompaña a la inversión pública era el resultado de una verdadera sucesión de olas de inversión, mediante las cuales los empresarios ampliaban febrilmente la capacidad de producción impulsando importaciones, adquisiciones de equipo nacional y construcción de nuevas instalaciones, con lo que la economía nacional ingresaba en una de las fases de auge más extraordinarias de toda su historia, el boom petrolero." (Rivera, 1986: 87).
} 
CUADRO 2. Ingreso per cápita: México y Baja California. A precios constantes de 1970 (miles de pesos).

\begin{tabular}{|c|c|c|c|c|c|c|}
\hline \multirow[b]{2}{*}{ Años } & \multicolumn{2}{|c|}{$\begin{array}{l}\text { Ingreso } \\
\text { per cápita }\end{array}$} & \multicolumn{2}{|c|}{$\begin{array}{l}\text { Indice de creci- } \\
\text { miento base } 1970\end{array}$} & \multicolumn{2}{|c|}{$\begin{array}{c}\text { Porcentaje de } \\
\text { crecimiento anual }\end{array}$} \\
\hline & México & B. C. & México & B. C. & México & B. C. \\
\hline 1970 & 8.51 & 12.49 & 100.00 & 100.00 & & \\
\hline 1971 & 8.57 & 13.00 & 100.67 & 104.06 & 0.67 & 4.06 \\
\hline 1972 & 8.98 & 12.64 & 105.55 & 101.16 & 4.84 & -2.78 \\
\hline 1973 & 9.41 & 13.18 & 110.58 & 105.49 & 4.77 & 4.28 \\
\hline 1974 & 9.65 & 13.80 & 113.40 & 110.45 & 2.55 & 4.70 \\
\hline 1975 & 9.85 & 14.55 & 115.74 & 116.45 & 2.06 & 5.43 \\
\hline 1976 & 10.03 & 13.91 & 117.85 & 111.33 & 1.82 & -4.39 \\
\hline 1977 & 10.13 & 14.34 & 119.08 & 114.80 & 1.04 & 3.11 \\
\hline 1978 & 10.71 & 15.12 & 125.91 & 120.98 & 5.74 & 5.39 \\
\hline 1979 & 11.42 & 15.55 & 134.25 & 124.43 & 6.62 & 2.85 \\
\hline 1980 & 12.09 & 15.92 & 142.05 & 127.45 & 5.81 & 2.43 \\
\hline 1981 & 12.74 & 16.33 & 149.70 & 130.68 & 5.38 & 2.53 \\
\hline 1982 & 12.38 & 15.71 & 145.49 & 125.74 & -2.82 & -3.78 \\
\hline 1983 & 11.47 & 14.77 & 134.77 & 118.24 & -7.37 & -5.97 \\
\hline 1984 & 11.63 & 14.57 & 136.72 & 116.59 & 1.45 & -1.40 \\
\hline 1985 & 11.71 & 14.29 & 137.59 & 114.38 & 0.63 & -1.89 \\
\hline 1986 & 11.28 & 14.19 & 132.62 & 113.59 & -3.61 & -0.69 \\
\hline 1987 & 11.03 & 14.10 & 129.68 & 112.83 & -2.22 & -0.67 \\
\hline 1988 & 10.93 & 13.99 & 128.51 & 111.96 & -0.90 & -0.77 \\
\hline
\end{tabular}

FUENTE: Cuadro 1

Ingreso per cápita $=\mathrm{PIB} /$ Población total.

De 1970 a 1976 no se aprecian grandes cambios en el IPC para México y para B. C., a pesar del crecimiento del PIB que se da en esos años. De 1977 a 1982 se presentó una mejoría relativa pero que no correspondió al ritmo de crecimiento acelerado que se dio; un supuesto "normal" hubiese sido que el IPC hubiera crecido alrededor del incrementado anual del PIB. A partir de 1982 se aprecia una caída constante del IPC, tal como se observa en la figura correspondiente.

Tomando el índice de crecimiento base 1970 para el IPC se aprecian interesantes situaciones del IPC: a) de 1977 a 1982 existe, en los valores 
del f́ndice, un ritmo mayor para México que para B. C.; b) a partir de 1982 se observa que el valor del índice cae con mayor velocidad en B. C. que en México.

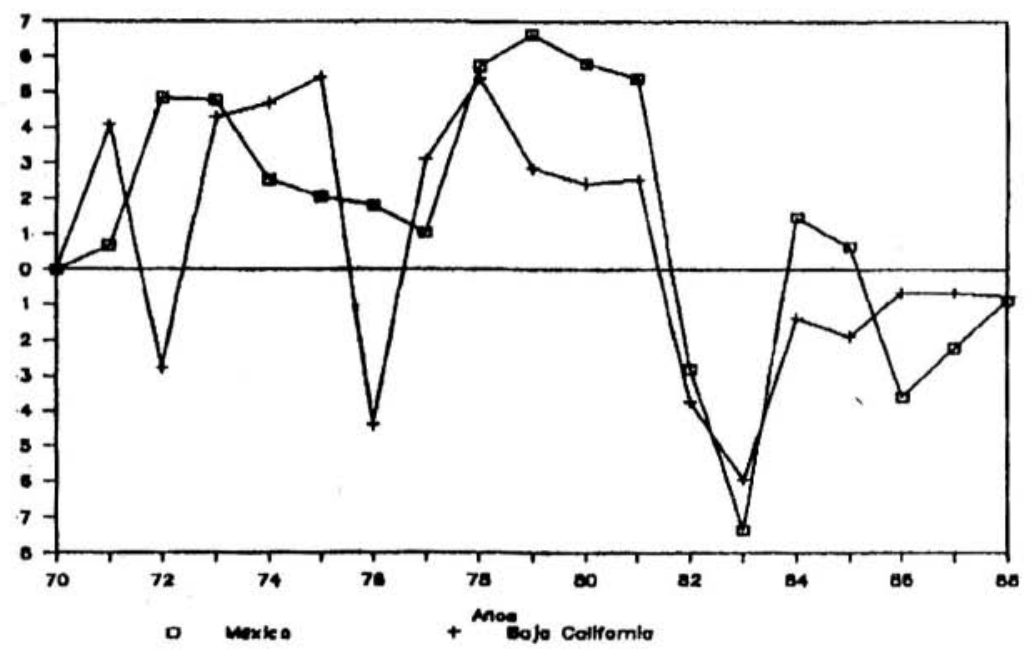

FIGURA 2. IPC: México-Baja California. Porcentaje de crecimiento anual.

Esta diferencia manifestada en contra por la entidad en los ritmos de crecimiento en el índice de 1970 del IPC puede ser explicada por dos razones básicamente: primera, que el "auge petrolero" no favoreció tanto a la entidad como al resto del país y, segunda, que los efectos de las devaluaciones y de la crisis de 1982 y 1986 fueron mayores en la entidad que en el país.

Ahora bien, del mismo cuadro 2 las columnas de los porcentajes de crecimiento anual son más representativas de la situación del IPC. Al respecto conviene señalar lo siguiente: a) en los años de 1972 y 1976 el porcentaje de crecimiento anual del IPC de B. C. cayó de una forma importante: -2.78 y -4.39 respectivamente; situación que no se dio a nivel nacional; b) la caída del porcentaje referido se inició en 1982; para 1983 es de -7.37 y $-5.97 \%$ para México y para Baja California. Desde entonces el IPC es negativo hasta 1988 para la entidad y no sucede lo mismo para el IPC promedio del país. Esta situación quizá demuestre que el bienestar social en la entidad sufra fuertes rezagos y que el crecimiento del PIB no está coadyuvando suficientemente a redistribuir la riqueza de una forma más equitativa. 
Una hipótesis explicativa respecto al punto anterior puede ser que el ingreso de la población en la entidad se ve más afectado por la inflación y por las devaluaciones del peso mexicano que en el resto del país.

En los cuadros 3 y 4 se presentan la tasa anual de inflación y los tipos de cambio peso/dólar. Como se aprecia en el cuadro 3, la inflación en la entidad fue 48.51 puntos superiores a la de México en 1982, y de 14.82 puntos superiores en 1987; lo cual habla ya de cómo las devaluaciones afectan al sistema de precios en la entidad.

CUADRO 3. Tasa anual de inflación México y Baja California. Inflación acumulada mensual a diciembre de cada año

\begin{tabular}{rrrrrr}
\hline Años & $\begin{array}{c}\text { México } \\
(1)\end{array}$ & $\begin{array}{c}\text { Mexicali } \\
(2)\end{array}$ & $\begin{array}{c}\text { Tijuana } \\
(3)\end{array}$ & $\begin{array}{r}\text { B. C. } \\
(4)\end{array}$ & $\begin{array}{r}\text { Dif. B.C.-Méx. } \\
(5)\end{array}$ \\
\hline 1970 & 4.80 & 4.80 & 4.80 & 4.80 & 0.00 \\
1971 & 5.20 & 5.19 & 5.19 & 5.19 & -0.01 \\
1972 & 5.50 & 5.53 & 5.53 & 5.53 & 0.03 \\
1973 & 21.30 & 20.92 & 20.92 & 20.93 & -0.37 \\
1974 & 20.70 & 20.03 & 20.03 & 20.03 & -0.67 \\
1975 & 11.20 & 10.59 & 10.59 & 10.59 & -0.61 \\
1976 & 27.20 & 25.62 & 25.62 & 25.63 & -1.57 \\
1977 & 20.70 & 20.75 & 20.75 & 20.76 & 0.06 \\
1978 & 16.20 & 16.22 & 16.22 & 16.22 & 0.02 \\
1979 & 20.00 & 19.43 & 19.43 & 19.44 & -0.56 \\
1980 & 29.80 & 23.51 & 25.84 & 24.10 & -5.70 \\
1981 & 28.70 & 20.92 & 22.68 & 21.50 & -7.20 \\
1982 & 98.80 & 145.88 & 149.41 & 147.31 & 48.51 \\
1983 & 80.80 & 79.34 & 78.91 & 78.97 & -1.83 \\
1984 & 59.20 & 56.05 & 57.14 & 56.60 & -2.60 \\
1985 & 63.70 & 67.80 & 66.60 & 67.18 & 3.48 \\
1986 & 105.70 & 103.30 & 111.02 & 107.61 & 1.91 \\
1987 & 159.20 & 171.01 & 176.25 & 174.02 & 14.82 \\
1988 & 51.70 & 55.16 & 57.57 & 56.54 & 4.84 \\
\hline
\end{tabular}

FUENTE: Indicadores económicos, varios años, Banco de México. En base al índice nacional y estatal de precios al consumidor. La tasa de inflación para B.C. se ponderó según los porcentajes de participación de los municipios de Mexicali y Tijuana en el PIB de la entidad. En promedio es de 47 y $53 \%$ respectivamente. 
CUADRO 4. Paridad del peso respecto al dólar de Estados Unidos.

Af̂os Pesos por dólar

\begin{tabular}{|c|c|c|c|c|c|}
\hline 1970 & 12.50 & & & & \\
\hline 1971 & 12.50 & & & & \\
\hline 1972 & 12.50 & & & & \\
\hline 1973 & 12.50 & & & & \\
\hline 1974 & 12.50 & & & & \\
\hline 1975 & 12.50 & & & & \\
\hline 1976 & 12.50 & & & & \\
\hline 1977 & 22.73 & & & v & \\
\hline 1978 & 22.72 & & & & \\
\hline 1979 & 22.80 & & & & \\
\hline 1980 & 23.26 & \multicolumn{2}{|c|}{ Mercado* } & \multicolumn{2}{|c|}{ Controlado** } \\
\hline 1981 & 26.23 & fin del año & promedio & fin del año & promedio \\
\hline 1982 & 89.90 & 148.50 & 57.18 & 96.48 & 57.44 \\
\hline 1983 & 143.94 & 161.35 & 150.29 & 143.93 & 120.17 \\
\hline 1984 & 188.87 & 209.97 & 185.19 & 192.56 & 167.77 \\
\hline 1985 & 346.56 & 447.50 & 310.28 & 371.50 & 256.96 \\
\hline 1986 & 771.81 & 915.00 & 637.88 & 923.00 & 611.35 \\
\hline 1987 & 1799.64 & 2227.50 & 1405.81 & 2198.50 & 1366.73 \\
\hline 1988 & 2277.13 & 2297.00 & 2297.50 & 2257.00 & 2257.00 \\
\hline
\end{tabular}

FUENTE: Indicadores económicos. Banco de México (NAFINSA/88, pp. 400-401); Para 1988: Indicadores econbmicos. Banco de México, agosto de 1989. En la columna pesos por dólar de 1982 en adelante es media ponderada.

" Desde 1982, corresponde al tipo "general" y "ordinario".

** Desde 1982, corresponde al tipo "preferencial".

La situación económica fronteriza de la entidad hace que los ingresos de la población sean muy sensibles a las devaluaciones - debido al alto grado de importaciones de bienes de consumo básico y duraderos que existe en la entidad-. También el sistema de precios relativos de la entidad se encuentra débil frente a cambios externos - debido a las altas cuotas de importación para los sectores comerciales e industriales-. Esta es una característica típicamente fronteriza: que el ingreso de la población fronteriza y que las actividades económicas de la entidad sean más vulnerables a los cambios de la economía internacional que en el resto del país. 


\section{COMPORTAMIENTO DEL SECTOR EXTERNO}

El estudio del sector externo puede efectuarse bajo dos ópticas: en relación a las variables que componen la cuenta corriente de la balanza de pagos y en relación a las implicaciones que tiene para la población el sector externo en su conjunto.

El objetivo de esta parte del trabajo es evaluar la dinámica del sector externo por medio de los indicadores per cápita, preferentemente del comercio exterior. No damos atención especial a la política económica nacional y fronteriza - pues ello requiere de mayor espacio del que disponemos-, pero presentamos un estudio empírico sobre la cuenta corriente de la balanza de pagos de México.

Algunas líneas generales sobre el comercio exterior mexicano ya se expusieron en la primera parte del trabajo; ahora es necesario presentar, someramente, los resultados empíricos. Posteriormente pasaremos al comercio exterior de B. C. y al estudio de los resultados de los indicadores per cápita del sector externo.

En el cuadro 5 se anotan los ingresos y egresos de la cuenta corriente de la balanza de pagos de México de 1970 a $1988 .^{5}$ Este cuadro se acompaña del cuadro 5.1 que presenta la balanza comercial de aquélla. Concentramos la atención en las balanzas porque éstas son más representativas de los fenómenos del sector externo que los valores absolutos de los ingresos y egresos.

Con base en el cuadro 5.1 se pueden señalar algunos fenómenos por fases:

- En la fase 1, la balanza total (columna 1) refleja fielmente la crisis de 1976. Después de un pequeño auge de las importaciones entre los affos de 1974 a 1976 - sin una correspondencia en las exportaciones-, la balanza comercial, deficitaria hasta 1982, se reduce no por un aumento en las exportaciones, sino por una drástica caída en las importaciones.

- La balanza en las transacciones fronterizas en esta fase es superavitaria, tal que para 1976 ésta es de $419 \mathrm{MD}$ (millones de dólares); compensando de cierta manera al déficit total.

5 Dividimos en tres fases los años que van de 1970 a 1988, igual que para el análisis de los ciclos económicos: fase 1: 1970 a 1976; fase 2: de 1977 a 1981 y fase 3: de 1982 a 1988.

6 "El desequilibrio externo reconoce tres causas inmediatas. La primera es la expansión de las importaciones. La segunda es el cada vez mayor egreso por pagos financieros ligados a una deuda extema también creciente. Por último, están los movimientos especulativos de capital, destacadamente la fuga de capitales." (López, 1983: 196). 
CUADRO 5. Ingresos y egresos de la cuenta corriente de la balanza de pagos. México (millones de dólares).

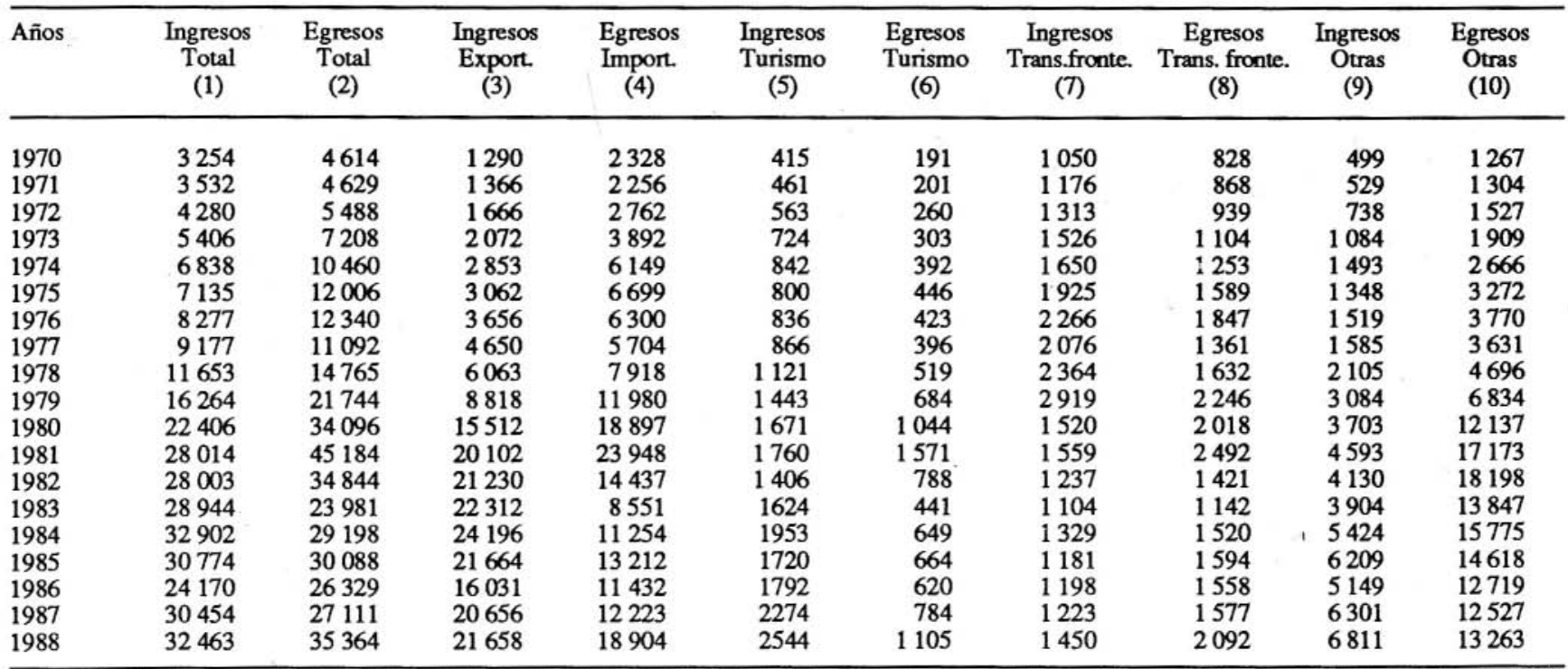

FUENTE: Indicadores económicos, Banco de México, (NAFINSA/88. p. 376). E. INEGI: Avances. Balanza Comercial. Nov. 1988. Para el año de 1988. Indicadores económicos del Banco de México, agosto de 1989. pp. 3-4. Incluye exportaciones petroleras, (las exportaciones son a precios FOB; libre a bordo). Las importaciones son a precios del CIF ingreso pp.7-8. Transacciones fronterizas. Los datos de 1982 en adelante no son comparables con los años anteriores por cambio de metodología de estimación. Aquí se ajustaron las series según los porcentajes anuales de crecimiento, ajustando la primera con la segunda metodología.

(9) Otras: Servicios por transformación, transporte, intereses, transferencias y otros.

(10) Otros. Incluye: utilidades netas al exterior, intereses pagados al exterior por el sector privado y banca, transferencias y otros. 
CUADRO 5.1. Balanza de cuenta corriente de la balanza de pagos. México. Ingresos-egresos (millones de dólares).

\begin{tabular}{lccccc}
\hline Años & $\begin{array}{c}\text { Balanza } \\
\text { Total } \\
(1)\end{array}$ & $\begin{array}{c}\text { Balanza } \\
\text { Comercial } \\
(2)\end{array}$ & $\begin{array}{c}\text { Balanza } \\
\text { Turismo } \\
(3)\end{array}$ & $\begin{array}{c}\text { Balanza } \\
\text { Fronte. } \\
(4)\end{array}$ & $\begin{array}{c}\text { Balanza } \\
\text { Otros } \\
(5)\end{array}$ \\
\hline 1970 & -1360 & -1038 & 224 & 222 & -768 \\
1971 & -1097 & -890 & 260 & 308 & -775 \\
1972 & -1208 & -1096 & 303 & 374 & -789 \\
1973 & -1802 & -1820 & 421 & 422 & -825 \\
1974 & -3622 & -3296 & 450 & 397 & -1173 \\
1975 & -4871 & -3637 & 354 & 336 & -1924 \\
1976 & -4063 & -2644 & 413 & 419 & -2251 \\
1977 & -1915 & -1054 & 470 & 715 & -2946 \\
1978 & -3112 & -1855 & 602 & 732 & -2591 \\
1979 & -5480 & -3162 & 759 & 673 & -3750 \\
1980 & -11690 & -3385 & 627 & -498 & -8434 \\
1981 & -17170 & -3846 & 189 & -933 & -12580 \\
1982 & -6841 & 6793 & 618 & -184 & -14068 \\
1983 & 4963 & 13761 & 1183 & -38 & -9943 \\
1984 & 3704 & 12942 & 1304 & -191 & -10351 \\
1985 & 686 & 8452 & 1056 & -413 & -8409 \\
1986 & -2159 & 4599 & 1172 & -360 & -7570 \\
1987 & 3343 & 8433 & 1490 & -354 & -6226 \\
1988 & -2901 & 2754 & 1439 & -642 & -6452 \\
\hline
\end{tabular}

FUENTE: Cuadro 5.

- Es interesante comparar la balanza comercial con la balanza de "otros" (columnas 2 y 5), ya que en esta última se encuentran medidas las utilidades netas al exterior, los intereses pagados al exterior y otras. De 1970 a 1975, la balanza "otros" es deficitaria en un grado cada vez mayor a la balanza comercial.

Para la fase 2, la cuenta corriente de la balanza de pagos refleja fenómenos de interés:

- En primer lugar resalta el escandaloso déficit en la balanza total en 1981 y su fuerte caída para 1982. 
- En la balanza comercial se presenta un déficit alrededor de 3,000 MD para toda la fase.

- Por primera vez en muchos años la balanza de transacciones fronterizas presenta un déficiten 1980, que casi se duplica para 1981, lo cual habla de un egreso fronterizo mayor que sus ingresos; esto se debió a la sobrevaluación en que se encontraba el peso mexicano, lo cual propició una avalancha de importaciones en la frontera como en ningún año.

- Es la balanza "otros" la que influye más a la balanza total en términos de su déficit, y no otra variable. Por lo tanto, para 1983, aunque se logró un superávit, éste no fue mayor porque se vio afectado en un alto porcentaje por la balanza deficitaria de la variable "otros"; lo cual demuestra que desde entonces la balanza comercial no es el problema más grave existente en la economía exterior de México.

Con la crisis de 1982, en la fase 3, la mayoría de las balanzas que estamos observando cambian de comportamiento. Se reduce drásticamente el déficit de la balanza total debido, de nuevo, a una reducción de las importaciones.

Es hasta 1983 cuando se obtiene una balanza total superavitaria, con cafdas negativas en 1986 y 1988. En los affos 1983 y 1984 se logran importantes avances positivos en la balanza comercial aś como en la de turismo. La balanza de transacciones fronterizas sigue siendo negativa, aunque nunca alcanza el déficit de 1981. Donde existe el problema deficitario es en la balanza "otros", que persiste en su comportamiento negativo; es pues esta variable la que absorbe los esfuerzos superavitarios de la balanza comercial y de turismo.

En el cuadro 6 se presentan las exportaciones e importaciones de México desagregadas por tipo de bien. Este cuadro se acompaffa también del cuadro 6.1 donde se observan las exportaciones e importaciones medidas por el índice de crecimiento base 1970=100.

En la primera parte del trabajo se seffalaron dos ideas sobre el comportamiento de la balanza comercial en México: a) Cuando existen años recesivos en la cconomía nacional, las exportaciones aumentan; mientras que en los años de crecimiento, las importaciones son las que aumentan. b) Las importaciones de bienes de capital son un elemento fundamental para comprender la dinámica del crecimiento de la economía mexicana.

Concentremos la atención en la balanza comercial; en la fase 1, las exportaciones de todos los tipos de bien aumentan. Las importaciones aumentan también, pero lo hacen con mayor volumen las de bienes de capital. Medida esta fase por el índice de crecimiento base $1970=100$, los 
CUADRO 6. Sector externo: Exportaciones e importaciones por tipo de bien. México (millones de dólares).

\begin{tabular}{|c|c|c|c|c|c|c|c|c|}
\hline \multirow[b]{2}{*}{ Años } & \multirow[b]{2}{*}{ Total } & \multicolumn{2}{|c|}{ EXPORTACIONES } & \multirow[b]{2}{*}{$\begin{array}{c}\text { Bienes }(* * *) \\
\text { de capital }\end{array}$} & \multirow[b]{2}{*}{ Total } & \multicolumn{2}{|c|}{ IMPORTACIONES } & \multirow[b]{2}{*}{$\begin{array}{c}\text { Bienes }(* * *) \\
\text { de capital }\end{array}$} \\
\hline & & $\begin{array}{l}\text { Bienes de } \\
\text { consumo(*) }\end{array}$ & $\begin{array}{l}\text { Bienes }(* *) \\
\text { intermedios }\end{array}$ & & & $\begin{array}{c}\text { Bienes de } \\
\text { consumo(*) }\end{array}$ & $\begin{array}{l}\text { Bienes }(* *) \\
\text { intermedios }\end{array}$ & \\
\hline 1970 & 1290 & 592.79 & 576.51 & 120.70 & 2338 & 197.69 & 771.27 & 1359.05 \\
\hline 1971 & 1366 & 594.33 & 598.11 & 173.56 & 2256 & 192.70 & 769.64 & 1293.66 \\
\hline 1972 & 1666 & 680.77 & 743.07 & 242.15 & 2762 & 266.78 & 929.96 & 1565.27 \\
\hline 1973 & 2072 & 871.82 & 827.53 & 37265 & 3892 & 373.78 & 1566.03 & 1952.19 \\
\hline 1974 & 2853 & 1029.97 & 1329.34 & 493.69 & 6149 & 511.39 & 2716.25 & 2921.36 \\
\hline 1975 & 3062 & 1215.46 & 1299.08 & 547.46 & 6699 & 488.10 & 2383.87 & 3827.02 \\
\hline 1976 & 3656 & 1505.19 & 1615.71 & 535.10 & 6300 & 462.76 & 2243.37 & 3593.87 \\
\hline 1977 & 4650 & 2261.26 & 1783.53 & 605.21 & 5704 & 467.97 & 2115.46 & 3120.57 \\
\hline 1978 & 6063 & 2573.17 & 2207.36 & 1282.47 & 7918 & 840.79 & 3059.62 & 4017.58 \\
\hline 1979 & 8818 & 3823.36 & 3153.30 & 1841.35 & 11980 & 1034.62 & 4192.95 & 6752.43 \\
\hline 1980 & 15512 & 5598.89 & 6250.98 & 3662.13 & 18897 & 2213.02 & 6542.31 & 10141.67 \\
\hline 1981 & 20102 & 6306.89 & 9328.11 & 4467.00 & 23948 & 2537.74 & 7825.45 & 13584.82 \\
\hline 1982 & 21230 & 7347.71 & 8572.17 & 5310.13 & 14437 & 1638.85 & 4858.72 & 7939.43 \\
\hline 1983 & 22312 & 6303.45 & 10357.29 & 5651.25 & 8551 & 1085.59 & 3277.58 & 4187.82 \\
\hline 1984 & 24196 & 5105.77 & 11490.37 & 7599.86 & 11254 & 1213.08 & 4493.69 & 5547.23 \\
\hline 1985 & 21664 & 1764.16 & 19475.80 & 424.04 & 13212 & 1081.92 & 8965.32 & 3164.76 \\
\hline 1986 & 16031 & 2563.00 & 12868.00 & 600.00 & 11432 & 845.93 & 7631.33 & 2954.74 \\
\hline 1987 & 20656 & 3691.82 & 16187.22 & 776.96 & 12223 & 768.06 & 8825.72 & 2629.22 \\
\hline 1988 & 21658 & 3894.33 & 17075.12 & 688.55 & 18903 & 1921.00 & 12951.00 & 4031.00 \\
\hline
\end{tabular}

FUENTE: Indicadores de comercio exterior, Banco de México. Indicadores del sector externo, Banco de México, varios años.

(NAFINSA/86, pp. 332-333. NAFINSA/88, pp. 390-391). Para 1987 y 1988: Indicadores económicos del Banco de MÉxico, agosto de 1989. Algunos años son elaboración propia en base a la estructura porcentual de los cuadros originales.

(*) Comprende ramas: productos alimenticios, bebidas, tabaco y otras, según SCN del INEGL.

$\left({ }^{* *}\right)$ Comprende ramas: textil, madera, papel, sustancias químicas y otras, según sCN del DNEGL.

(***) Comprende ramas: productos metálicos, maquinaria y equipos, según SCN del INECL. 
CUADRO 6.1. Sector externo: Exportaciones e importaciones por tipo de bien, México. Índice de crecimiento base 1970.

\begin{tabular}{|c|c|c|c|c|c|c|c|c|}
\hline \multirow[b]{2}{*}{ Años } & \multirow[b]{2}{*}{ Total } & \multicolumn{3}{|c|}{ EXPORTACIONES } & \multirow[b]{2}{*}{ Total } & \multicolumn{2}{|c|}{ IMPORTACIONES } & \multirow[b]{2}{*}{$\begin{array}{c}\text { Bienes } \\
\text { de capital }\end{array}$} \\
\hline & & $\begin{array}{l}\text { Bienes de } \\
\text { consumo }\end{array}$ & $\begin{array}{c}\text { Bienes } \\
\text { intermedios }\end{array}$ & $\begin{array}{c}\text { Bienes } \\
\text { de capital }\end{array}$ & & $\begin{array}{c}\text { Bienes de } \\
\text { consumo }\end{array}$ & $\begin{array}{c}\text { Bienes } \\
\text { intermedios }\end{array}$ & \\
\hline 1970 & 100.00 & 100.00 & 100.00 & 100.00 & 100.00 & 100.00 & 100.00 & 100.00 \\
\hline 1971 & 105.89 & 100.26 & 103.75 & 143.79 & 96.91 & 97.48 & 99.79 & 95.19 \\
\hline 1972 & 129.15 & 114.84 & 128.89 & 200.62 & 118.64 & 134.95 & 120.58 & 115.17 \\
\hline 1973 & 160.62 & 147.07 & 143.54 & 308.73 & 167.18 & 189.08 & 203.05 & 143.64 \\
\hline 1974 & 221.16 & 173.75 & 230.58 & 409.01 & 264.13 & 258.69 & 352.18 & 214.96 \\
\hline 1975 & 237.36 & 205.04 & 225.33 & 453.55 & 287.76 & 246.91 & 309.09 & 281.60 \\
\hline 1976 & 283.41 & 253.92 & 280.26 & 443.32 & 270.62 & 234.09 & 290.87 & 264.44 \\
\hline 1977 & 360.47 & 381.46 & 309.37 & 501.40 & 245.02 & 236.72 & 274.28 & 229.61 \\
\hline 1978 & 470.00 & 434.08 & 382.88 & 1062.50 & 340.12 & 425.32 & 396.70 & 295.62 \\
\hline 1979 & 683.57 & 644.98 & 546.96 & 1525.51 & 514.60 & 523.36 & 543.64 & 496.85 \\
\hline 1980 & 1202.48 & 944.51 & 1084.28 & 3033.99 & 811.73 & 1119.46 & 848.26 & 746.23 \\
\hline 1981 & 1558.29 & 1063.94 & 1618.03 & 3700.80 & 1028.69 & 1283.72 & 1014.62 & 999.58 \\
\hline 1982 & 1645.74 & 1239.52 & 1486.90 & 4399.31 & 620.15 & 829.01 & 629.97 & 584.19 \\
\hline 1983 & 1729.61 & 1063.36 & 1796.55 & 4681.92 & 367.31 & 549.15 & 424.96 & 308.14 \\
\hline 1984 & 1875.66 & 861.32 & 1993.09 & 6296.30 & 483.42 & 613.64 & 582.64 & 408.17 \\
\hline 1985 & 1679.38 & 297.61 & 3378.22 & 351.31 & 567.53 & 547.29 & 1162.42 & 232.87 \\
\hline 1986 & 1242.71 & 432.37 & 2232.05 & 497.09 & 491.07 & 427.91 & 989.45 & 217.41 \\
\hline 1987 & 1601.24 & 622.79 & 2807.79 & 643.69 & 525.04 & 388.53 & 1144.32 & 193.46 \\
\hline 1988 & 1678.91 & 656.95 & 2961.80 & 570.45 & 811.98 & 971.74 & 1679.19 & 296.60 \\
\hline
\end{tabular}

FUENTE: Cuadro 6. 
resultados en las exportaciones son que, para 1976, este valor es alrededor de 270 para todos los tipos de bien. En cambio, en importaciones resalta el aumento en los bienes intermedios, bienes de capital y por último los bienes de consumo por orden de importancia.

En la fase 2, las exportaciones de bienes intermedios ganan una ventaja frente a las exportaciones de bienes de consumo; desde entonces se puede afirmar que el país se convertía en exportador de bienes manufacturados con un importante avance en las exportaciones de bienes de capital.

El problema más grave fue el de las importaciones de bienes de capital, que en 1981 logra su más alto valor en el período estudiado (1970 a 1988): antecedente inmediato e inevitable de la crisis de 1982. En términos del índice, las exportaciones de bienes de capital logra el mayor valor, y en importaciones las de bienes de consumo.

Por último, en la fase 3, las exportaciones de bienes manufactureros logran consolidarse como el de mayor valor, tal que medido por el índice base 1970, para 1988 su crecimiento es de 2,961 puntos del valor del índice, mientras que en bienes de consumo es de 657 y en bienes de capital de 570 en los valores del índice para este último año.

En las importaciones, los bienes de capital se encuentran en 297 del valor del índice base, siendo el más bajo de los otros dos tipos de bienes importados. Esto último demuestra el estancamiento en que se encuentra la economía nacional: al no existir importantes volúmenes de importación de bienes de capital, el aparato productivo se inmoviliza, ya que no existe suficiente y adecuada producción de bienes de capital nacionales.

Pasando al caso concreto de la balanza comercial de Baja California, que se presenta en el cuadro 7, algunos fenómenos específicos destacan:

1) Las exportaciones poseen un alto grado de estabilidad a través de los años, de 1970 a 1988 se mueven alrededor de 140 millones de dólares; los cambios de paridad peso/dólar no generan ningún cambio importante en éstas. ${ }^{7}$ Caso contrario al de México, donde los cambios de paridad de la moneda nacional sí producen ajustes importantes.

2) Son en las importaciones donde los ajustes económicos y monetarios se resienten de manera palpable: en la primera fase existe un comportamiento sin cambios bruscos de su valor, en cambio, en la fase 2, hay un crecimiento veloz de las importaciones que termina en 1982; desde entonces las importaciones en la entidad se encuentran a niveles de la fase 1.

7 Las exportaciones aquí presentadas no incluyen las exportaciones de la "industria maquiladora"; ya que éstas cumplen otra función dentro de la entidad: son exportaciones basadas no en el consumo nacional de materias primas, sino en la mano de obra y prestaciones especiales de política económica. Por ende, este tipo de exportaciones quedan fuera de nuestro objetivo de estudio, aunque no por ello se deben de menospreciar. 
CUADRO 7. Balanza de cómercio exterior de Baja California. (Miles de dólares).

\begin{tabular}{|c|c|c|c|}
\hline Años & $\begin{array}{l}\text { Exportaciones } \\
\text { (1) }\end{array}$ & $\begin{array}{c}\text { Importaciones } \\
\text { (2) }\end{array}$ & $\begin{array}{l}\text { Balanza comercial } \\
(3)=(1)-(2)\end{array}$ \\
\hline 1970 & 125139 & 107716 & 17423 \\
\hline 1971 & 121040 & 294960 & -173920 \\
\hline 1972 & 145280 & 354000 & -208720 \\
\hline 1973 & 323840 & 486640 & -162800 \\
\hline 1974 & 108160 & 384640 & -276480 \\
\hline 1975 & 125195 & 409068 & -283873 \\
\hline 1976 & 152457 & 349922 & -197465 \\
\hline 1977 & 156216 & 441036 & -284820 \\
\hline 1978 & 154310 & 472352 & -318042 \\
\hline 1979 & 153896 & 612313 & -458417 \\
\hline 1980 & 174072 & 665975 & -491903 \\
\hline 1981 & 168508 & 1055532 & -887024 \\
\hline 1982 & 132392 & 902444 & -770052 \\
\hline 1983 & 124984 & 430819 & -305835 \\
\hline 1984 & 134100 & 394200 & -260100 \\
\hline 1985 & 137533 & 401128 & -263595 \\
\hline 1986 & 140121 & 377882 & -237760 \\
\hline 1987 & 135963 & 409277 & -273315 \\
\hline 1988 & 136070 & 473809 & -337739 \\
\hline
\end{tabular}

FUENTE: SIC Anuario Estadístico de Comercio Exterior, para los años de 1971 a 1974. Para los años 1970, 1975 y 1980: Baja California: estadísticas básicas 1981. Gobierno del Estado de B. C. Para los años de 1981 a 1984: "II Informe de Gobierno" Gobierno de B. C. , p. 86. Para los años de 1976 a 1979 y 1985 a 1988 estimaciones por el autor en base al comportamiento nacional del comercio exterior nacional, tipo de cambio, transacciones fronterizas y PIB B. C.

3) La balanza comercial de la entidad es permanentemente deficitaria en todo el período; sus máximos valores se encuentran en la fase 2, cuando precisamente se ubica un mayor crecimiento económico. El déficit ha sido mayor en la fase 3 que en la fase 1. Esta situación nos habla de un desequilibrio de largo plazo en dicha balanza que no responde a lo que está sucediendo a nivel nacional en los últimos años. Esta es otra especificidad 
de la economía de B. C.: el comportamiento diferencial y deficitario de la balanza comercial de la entidad respecto a la dinámica nacional. ${ }^{8}$

Pasemos ahora a evaluar los resultados de algunos de los indicadores per cápita (PC) del sector externo para México y Baja California. Para tal efecto, se construyeron los cuadros $8,8.1$ y 8.2 y la figura 3 para los per cápita de las importaciones y exportaciones de México y Baja California. El primer cuadro expone los indicadores per cápita en dólares corrientes; en el segundo se mide el movimiento de los indicadores por medio del índice de crecimiento base $1970=100$ (índice 1970); y en el cuadro 8.2 por su porcentaje de crecimiento anual (porcentaje anual).

Para una mejor exposición, procederemos como se hizo en los pasados párrafos: por fases. Además, se recomienda al lector leer los resultados para los siguientes años: 1976, 1982-1983, y 1986; para terminar con la situación del año de 1988.

\section{Análisis por fases:}

\section{Fase 1:}

a) Los ingresos totales PC de México son menores a los egresos PC totales; en 1976 eran 130 contra 194 dólares respectivamente. Por su parte, las exportaciones totales PC son mayores a las exportaciones manufactureras, pero las importaciones PC son mayores a las exportaciones PC, casi por el doble. Para B. C., las exportaciones PC son casi tres veces menores que las importaciones PC. En cambio los ingresos en las transacciones fronterizas son un poco mayor a los egresos PC (cuadro 8).

b) En términos del índice 1970, la totalidad de los PC del sector externo habían aumentado al doble para México. En cambio en B. C. se presenta otra situación para el sector externo PC: las exportaciones PC de la entidad se encontraban a nivel de 1970, las importaciones PC en un valor de 263 del índice (cuadro 8.1).

8 Para un investigador de la entidad, el crecimiento económico de B. C. se encuentra sumamente relacionado al tipo de cambio peso/dólar y a la demanda efectiva. Para la fase 3 , dice el autor que: "... habría que acotar la naturaleza crítica de esta fase, persistentemente matizada por los deslizamientos sucesivos de tipo de cambio, que acompañan la caída notable de los ingresos reales de la población. En este sentido, podría plantearse la hipótesis de que, a diferencia de lo ocurrido entre 1970 y 1975 , cuando no se registraron movimientos en el tipo de cambio $-\mathrm{y}$ por lo mismo se produjo una sobrevaluación considerable-, en esta ocasión ha sido justamente la caída del tipo de cambio lo que ha contenido en buena medida los efectos de recomposición que anteriormente acompañaban al proceso inflacionario.

"La contracción del mercado local se ha visto parcialmente compensada por la reorientación de la demanda hacia un mayor consumo de productos nacionales, así como por la renovación de estímulos a la expansión de la actividad maquiladora. Ambos efectos han permitido que se minimicen los impactos de la recesión sobre la estructura industrial regional." (Sández, 1987: 50). 
CUADRO 8. Indicaciones per cápita del sector externo para México y Baja California (en dólares corrientes).

\begin{tabular}{|c|c|c|c|c|c|c|c|c|c|c|}
\hline \multirow[b]{2}{*}{ Años } & \multirow[b]{2}{*}{$\begin{array}{l}\text { Ingreso } \\
\text { total } \\
(1)\end{array}$} & \multicolumn{4}{|c|}{ PER CAPITAS DE MEXICO } & \multicolumn{5}{|c|}{ PER CAPITAS B. C. } \\
\hline & & $\begin{array}{c}\text { Egreso } \\
\text { total } \\
\text { (2) }\end{array}$ & $\begin{array}{c}\mathrm{X}^{*} \\
\text { totales } \\
(3)\end{array}$ & $\begin{array}{l}\text { X de bienes } \\
\text { manufactureros } \\
\text { (4) }\end{array}$ & $\begin{array}{l}\mathrm{M}^{* *} \\
\text { totales } \\
(5)\end{array}$ & $\begin{array}{c}\text { M de bienes } \\
\text { de consumo } \\
(6)\end{array}$ & $\begin{array}{c}\mathrm{X}^{*} \\
\text { totales } \\
(7)\end{array}$ & $\begin{array}{c}\text { M** } \\
\text { totales } \\
(8)\end{array}$ & $\begin{array}{l}\text { Ingresos } \\
\text { fronte. } \\
(9)\end{array}$ & $\begin{array}{l}\text { Egresos } \\
\text { fronte. } \\
\text { (10) }\end{array}$ \\
\hline 1970 & 62.32 & 88.36 & 24.70 & 11.04 & 44.58 & 3.79 & 140.63 & 121.05 & 413.00 & 372.21 \\
\hline 1971 & 65.37 & 85.67 & 25.28 & 11.07 & 41.75 & 3.57 & 131.44 & 320.31 & 446.98 & 377.04 \\
\hline 1972 & 76.55 & 98.16 & 29.80 & 13.29 & 49.40 & 4.77 & 152.42 & 371.41 & 482.15 & 394.07 \\
\hline 1973 & 93.44 & 124.59 & 35.82 & 14.30 & 67.27 & 6.46 & 328.20 & 493.19 & 541.29 & 447.55 \\
\hline 1974 & 114.23 & 174.73 & 47.66 & 22.21 & 102.72 & 8.54 & 105.87 & 376.49 & 565.26 & 490.58 \\
\hline 1975 & 115.19 & 193.83 & 49.43 & 20.97 & 108.15 & 7.88 & 118.33 & 386.64 & 636.81 & 600.75 \\
\hline 1976 & 130.52 & 194.60 & 57.65 & 25.48 & 99.35 & 7.30 & 139.12 & 319.32 & 723.73 & 674.18 \\
\hline 1977 & 141.36 & 170.86 & 71.63 & 27.47 & 87.86 & 7.21 & 137.61 & 388.50 & 640.04 & 479.55 \\
\hline 1978 & 175.34 & 222.16 & 91.23 & 33.21 & 119.14 & 12.65 & 131.19 & 401.58 & 703.43 & 554.99 \\
\hline 1979 & 239.04 & 319.58 & 129.60 & 46.35 & 176.07 & 15.21 & 126.25 & 502.33 & 838.15 & 737.04 \\
\hline 1980 & 321.67 & 489.50 & 222.70 & 89.74 & 271.29 & 31.77 & 137.78 & 527.13 & 421.09 & 638.91 \\
\hline 1981 & 392.63 & 633.27 & 281.74 & 130.74 & 335.64 & 35.57 & 129.01 & 808.13 & 477.44 & 667.77 \\
\hline 1982 & 383.50 & 477.19 & 290.74 & 117.40 & 197.71 & 22.44 & 98.03 & 668.19 & 366.36 & 368.25 \\
\hline 1983 & 387.63 & 321.16 & 298.81 & 138.71 & 114.52 & 14.54 & 89.48 & 308.44 & 316.15 & 286.16 \\
\hline 1984 & 431.18 & 382.64 & 317.09 & 150.58 & 147.48 & 15.90 & 92.81 & 272.83 & 367.93 & 368.21 \\
\hline 1985 & 394.85 & 386.05 & 277.96 & 249.89 & 169.52 & 13.88 & 92.01 & 368.34 & 316.02 & 373.22 \\
\hline 1986 & 303.77 & 330.90 & 201.48 & 161.72 & 143.68 & 10.63 & 90.82 & 244.94 & 310.61 & 353.45 \\
\hline 1987 & 375.05 & 333.88 & 254.39 & 199.35 & 150.53 & 9.46 & 85.37 & 256.97 & 307.15 & 346.55 \\
\hline 1988 & 391.88 & 426.90 & 261.45 & 206.13 & 228.20 & 23.19 & 82.74 & 288.09 & 352.66 & 445.20 \\
\hline
\end{tabular}

FUENTE: Para la población de México y Baja California cuadro 1. Para las variables de México: Cuadro 5 . Para Baja California cuadros 6 y 7. En las transacciones fronterizas se dieron los siguientes porcentajes para Baja California: De 1970 a 1980 en ingresos $35 \%$ y de 1981 a 1988 del $40 \%$. De 1970 a 1980 en egresos $40 \%$ y de 1981 a 1988 del 35\%; en base a varios estudios del Banco de México (estos datos deben interpretarse con cuidado, pues son estimaciones)

* $\mathrm{X}=$ exportaciones

** $\mathrm{M}=$ importaciones 
CUADRO 8.1. Indicadores per cápita del sector externo para México y Baja California. (Índice de crecimiento base $1970=100$ ).

\begin{tabular}{|c|c|c|c|c|c|c|c|c|c|c|}
\hline \multirow[b]{2}{*}{ Años } & \multirow[b]{2}{*}{$\begin{array}{c}\text { Ingreso } \\
\text { total } \\
\text { (1) }\end{array}$} & \multicolumn{4}{|c|}{ PER CÁPTTAS DE MÉXICO } & \multirow[b]{2}{*}{$\begin{array}{c}\text { M de bienes } \\
\text { de consumo } \\
\text { (6) }\end{array}$} & \multicolumn{3}{|c|}{ PER CÁPITAS B. C. } & \multirow[b]{2}{*}{$\begin{array}{c}\text { Egresos } \\
\text { fronte. } \\
\text { (10) }\end{array}$} \\
\hline & & $\begin{array}{c}\text { Egreso } \\
\text { total } \\
(2)\end{array}$ & $\begin{array}{l}X(*) \\
\text { totales } \\
(3)\end{array}$ & $\begin{array}{c}\text { X de bienes } \\
\text { manufactureros } \\
\text { (4) }\end{array}$ & $\begin{array}{l}M(* *) \\
\text { totales } \\
(5)\end{array}$ & & $\begin{array}{c}X(*) \\
\text { totales } \\
(7)\end{array}$ & $\begin{array}{c}\mathrm{M}(*) \\
\text { totales } \\
(8)\end{array}$ & $\begin{array}{l}\text { Ingresos } \\
\text { fronte. } \\
\text { (9) }\end{array}$ & \\
\hline 1970 & 100.00 & 100.00 & 100.00 & 100.00 & 100.00 & 100.00 & 100.00 & 100.00 & 100.00 & 100.00 \\
\hline 1971 & 104.90 & 96.96 & 102.34 & 100.26 & 93.65 & 94.20 & 93.46 & 264.60 & 108.23 & 101.30 \\
\hline 1972 & 122.85 & 111.09 & 120.62 & 120.38 & 110.81 & 126.04 & 108.38 & 306.81 & 116.74 & 105.87 \\
\hline 1973 & 149.95 & 141.01 & 144.98 & 129.56 & 150.90 & 170.66 & 233.37 & 407.42 & 131.06 & 120.24 \\
\hline 1974 & 183.31 & 197.75 & 192.92 & 201.14 & 230.40 & 225.65 & 75.28 & 311.01 & 136.87 & 131.80 \\
\hline 1975 & 184.85 & 219.36 & 200.10 & 189.96 & 242.58 & 208.15 & 84.14 & 319.40 & 154.19 & 161.40 \\
\hline 1976 & 209.46 & 220.23 & 233.38 & 230.78 & 222.84 & 192.76 & 98.93 & 263.78 & 175.24 & 181.13 \\
\hline 1977 & 226.84 & 193.37 & 289.94 & 248.84 & 197.08 & 190.41 & 97.85 & 320.93 & 154.97 & 128.84 \\
\hline 1978 & 281.37 & 251.43 & 369.28 & 300.83 & 267.23 & 334.17 & 93.28 & 331.74 & 170.32 & 149.11 \\
\hline 1979 & 383.59 & 361.68 & 524.61 & 419.78 & 394.94 & 401.66 & 89.78 & 414.97 & 202.94 & 198.02 \\
\hline 1980 & 516.19 & 553.98 & 901.46 & 812.84 & 608.52 & 839.22 & 97.97 & 435.45 & 101.96 & 171.65 \\
\hline 1981 & 630.06 & 716.69 & 1140.45 & 1184.16 & 752.85 & 939.49 & 91.74 & 667.58 & 115.60 & 179.41 \\
\hline 1982 & 615.41 & 540.05 & 1176.90 & 1063.32 & 443.48 & 592.85 & 69.70 & 551.98 & 88.71 & 98.94 \\
\hline 1983 & 622.04 & 363.47 & 1209.55 & 1256.36 & 256.87 & 384.03 & 63.63 & 254.79 & 76.55 & 76.88 \\
\hline 1984 & 691.92 & 433.04 & 1283.53 & 1363.89 & 330.81 & 419.92 & 66.00 & 225.38 & 89.09 & 98.92 \\
\hline 1985 & 633.63 & 436.90 & 1125.17 & 2236.37 & 380.24 & 366.68 & 65.42 & 221.67 & 76.52 & 100.27 \\
\hline 1986 & 487.47 & 374.49 & 815.56 & 1464.83 & 322.27 & 280.83 & 64.58 & 202.34 & 75.21 & 94.96 \\
\hline 1987 & 601.86 & 377.86 & 1029.73 & 1805.64 & 337.65 & 249.85 & 60.70 & 212.28 & 74.37 & 93.11 \\
\hline 1988 & 628.87 & 483.14 & 1058.32 & 1866.99 & 511.87 & 612.54 & 58.83 & 237.99 & 85.39 & 119.61 \\
\hline
\end{tabular}

FUENTE: Cuadro 8. 


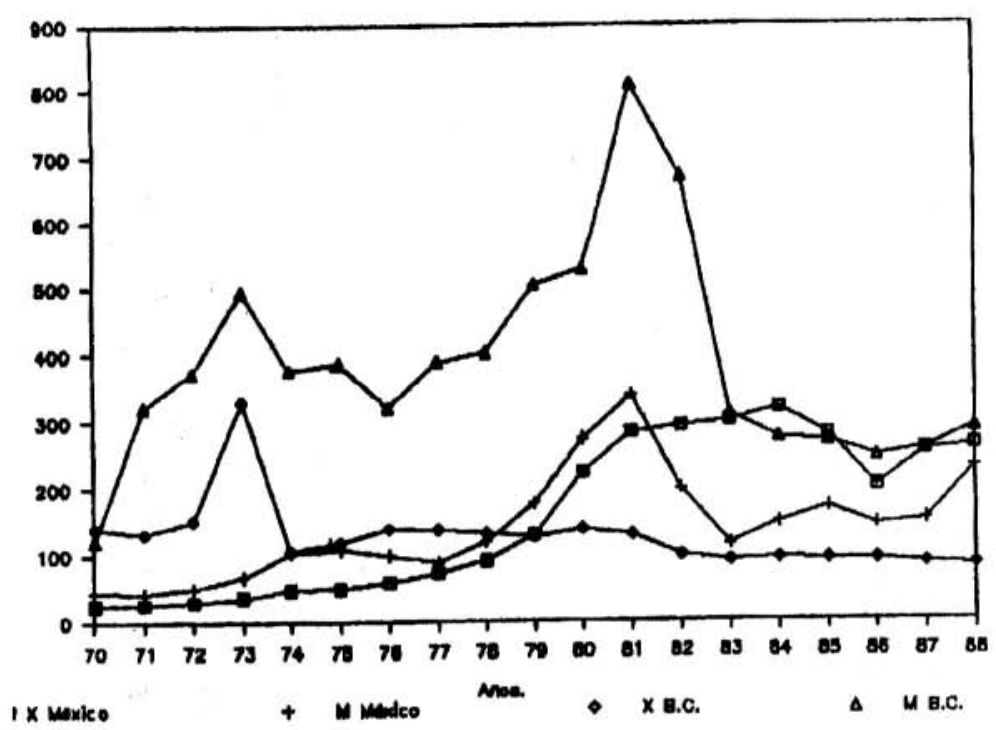

FIGURA 3. Sector externo per cápita. México y Baja California a dólares corrientes.

c) En términos de porcentaje anual los PC para México más altos son en 1974 y los más bajos en los años de 1971 y 1976. Para B. C. los años de mayor cambio también fueron los de 1974 y 1976. En este último afio las importaciones PC disminuyeron en $-17 \%$ y a nivel nacional en $-8 \%$, lo cual habla de los impactos de las devaluaciones de aquel año (cuadro 8.2).

d) Conclusión: comparando el sector externo PC de México con el de Baja California se aprecia, en primer lugar, que la entidad sufrió un estancamiento en las exportaciones PC, situación que no se dio a nivel nacional; en segundo lugar, que las importaciones PC de B. C. son mucho mayores que las de México. En tercer lugar, que los ingresos fronterizos PC son mayores a los egresos en los mismos términos. Y, por último, que la crisis de 1976 no afectó a los PC de las transacciones fronterizas pero sí lo hizo con las importaciones PC de la entidad.

Fase 2:

a) Como es de esperarse, a nivel nacional se generan fuertes cambios en los PC del sector externo, tal que el ingreso total PC cambia de 141 a 392 dólares de 1977 a 1981, pero los egresos totales lo hacen de 171 a 633 dólares para los mismos años. Las exportaciones totales PC para el país 
logran un aumento sustancial: de 72 a 281 dólares para aquellos mismos años; y las importaciones PC pasaron de 88 a 336 dólares (cuadro 8).

Para la entidad los cambios no son tan fuertes, lo cual posiblemente se deba a que, en el "auge petrolero", ésta no participó ni fue beneficiada por los ingresos generados en la exportación petrolera. En efecto, para los años de 1977 a 1981 los PC en dólares son: en exportaciones de 138 a 129 dólares; en las importaciones PC sí hay un cambio: pasa de 389 a 808 dólares; en los ingresos de las transacciones fronterizas hay una pequeña baja y un pequeño aumento en los egresos.

b) En términos del índice 1970, el cambio más importante se da a nivel nacional en las exportaciones PC y en las exportaciones manufactureras; pero las importaciones totales no alcanzan el ritmo de crecimiento de las importaciones PC de bienes de consumo. Las primeras tienen un índice de 753 y las segundas de 939. Para la entidad, el índice de 1970 tiene una dinámica de nuevo diferente al resto del país: un estancamiento visible en las exportaciones PC. Un aumento del doble en las importaciones PC: para 1981 el valor del índice es de 667, inferior al nacional. Un retroceso considerable en los ingresos por transacciones fronterizas y un aumento, no muy significativo si se compara con los valores del índice a nivel nacional, en los egresos fronterizos PC (cuadro 8.1).

c) En términos del porcentaje anual la mayoría de los indicadores son positivos a nivel nacional, aunque es en el año de 19.80 donde se logran los mayores crecimientos porcentuales, principalmente en las importaciones de bienes de consumo, que de un año a otro crecieron $108 \%$. Esta situación no se cumplió para la entidad: hay un porcentaje negativo en las exportaciones PC y aumentos fuertes en las importaciones PC en ciertos años $(1977,1979$ y 1981) y aumentos muy pequeños (1978 y 1980). En los ingresos de las transacciones fronterizas PC existe una drástica caída del $50 \%$ en 1980 (cuadro 8.2).

d) Conclusiones: el aumento en las importaciones PC para B. C. no fue tan elevado como el que se dio a nivel nacional, pero la entidad se benefició con un crecimiento considerable de aquellas importaciones PC; situación que para nada sucedió en las exportaciones. En los indicadores PC de las transacciones fronterizas aparece un equilibrio relativo en el porcentaje anual de crecimiento.

Fase 3:

a) A nivel nacional se inicia una caída en la mayoría de los indicadores PC del sector externo. La mayor caída se aprecia en las importaciones: de 336 a 198 dólares para los años de 1981 a 1982. Los ingresos totales PC 
parecen estabilizarse alrededor de 380 dólares durante toda esta fase, los egresos lo hacen también alrededor de 330 dólares (cuadro 8).

En cuanto a las exportaciones totales PC se tiene una situación de equilibrio relativo, aunque las exportaciones manufactureras PC tienden al crecimiento. Para la entidad, las importaciones PC pasan de 668 a 288 dólares de 1982 a 1988. Para este último año las importaciones PC de la entidad fueron casi iguales a la nacional. Además, se aprecia para B. C. una fuerte estabilidad en las exportaciones PC y en los PC de las transacciones fronterizas.

b) En cuanto al índice 1970 se observa que a nivel nacional el ingreso total PC se estabiliza alrededor de 600 puntos y que los egresos totales en 400 puntos del índice 1970. En cuanto a las exportaciones e importaciones totales PC, se encuentra una situación similar a las anteriores. Esta situación no sucede en las exportaciones manufactureras, pues $\mathrm{el}$ índice pasa de 1,063 a 1,866 puntos de 1982 a 1988 , lo cual ya habla de una estrategia exportadora de bienes manufactureros por parte del país; esto responde ya a la estrategia de largo plazo para apuntalar un elemento básico del modelo secundario exportador que planteamos en la primera parte del presente trabajo (cuadro 8.1).

La situación de la entidad es otra: una caída hasta de 50 puntos en las exportaciones PC; en las importaciones PC se pasa de 552 a 238 en los valores del índice. En los ingresos $\mathrm{PC}$ de las transacciones fronterizas, como de cierta manera en los egresos, los valores del índice son menores a los existentes en 1970, más en los ingresos que en los egresos.

c) En términos de los porcentajes de crecimiento anual, a nivel nacional se aprecia una fuerte caída de $-23 \mathrm{en}$ los ingresos totales PC y un aumento similar para 1987. En cuanto a los egresos totales PC la mayor cafda se encuentra en 1983 , de $-33 \%$, y para 1986 de $-14 \%$; en el mismo indicador se observa una recuperación sustancial en 1988 del $28 \%$. Las exportaciones totales y manufactureras tienden a tener un porcentaje anual positivo. En cuanto a las importaciones PC habría que señalar que para los años de 1982 y 1983, su caída es alrededor del $-41 \%$, posteriormente tiene tasas positivas, hasta 1986; pero en las importaciones de bienes de consumo básico existe una tendencia a tener tasas negativas, con excepción de 1988 que aumenta $145 \%$ (cuadro 8.2 ).

La entidad, por su parte, tiene otra dinámica: curiosamente de 1981 a 1982 las exportaciones PC caen en un -24\%; las importaciones PC caen también pero un af̂o después, en 1983, en un 53\% - mayor que la nacional-y es hasta 1987 que logra un porcentaje positivo, apenas de un 
CUADRO 8.2. Indicadores per cápita del sector externo para México y Baja California. (Porcentaje de crecimiento anual).

\begin{tabular}{|c|c|c|c|c|c|c|c|c|c|c|}
\hline \multirow[b]{2}{*}{ Años } & \multirow[b]{2}{*}{$\begin{array}{c}\text { Ingreso } \\
\text { total } \\
(1)\end{array}$} & \multicolumn{4}{|c|}{ PER CÁPITAS DE MÉXICO } & \multicolumn{5}{|c|}{ PER CÁPITAS B.C. } \\
\hline & & $\begin{array}{c}\text { Egreso } \\
\text { total } \\
\text { (2) }\end{array}$ & $\begin{array}{c}\mathrm{X}(*) \\
\text { totales } \\
(3)\end{array}$ & $\begin{array}{c}\mathrm{X} \text { de bienes } \\
\text { manufactureros } \\
\text { (4) }\end{array}$ & $\begin{array}{c}\mathrm{M}(* *) \\
\text { totales } \\
(5)\end{array}$ & $\begin{array}{l}\text { M de bienes } \\
\text { de consumo } \\
\text { (6) }\end{array}$ & $\begin{array}{c}X(*) \\
\text { totales } \\
(7)\end{array}$ & $\begin{array}{c}\mathrm{M}\left({ }^{*}\right) \\
\text { totales } \\
(8)\end{array}$ & $\begin{array}{l}\text { Ingresos } \\
\text { fronte. } \\
(9)\end{array}$ & $\begin{array}{c}\text { Egresos } \\
\text { fronte. } \\
(10)\end{array}$ \\
\hline \multicolumn{11}{|l|}{1970} \\
\hline 1971 & 4.90 & -3.04 & 2.34 & 0.26 & -6.35 & -5.80 & -6.54 & 164.60 & 8.23 & 1.30 \\
\hline 1972 & 17.11 & 14.58 & 17.87 & 20.07 & 18.32 & 33.79 & 15.96 & 15.95 & 7.87 & 4.52 \\
\hline 1973 & 22.07 & 26.93 & 20.19 & 7.63 & 36.18 & 35.40 & 115.32 & 32.79 & 12.27 & 13.57 \\
\hline 1974 & 22.24 & 40.24 & 33.07 & 55.24 & 52.69 & 32.22 & -67.74 & -23.66 & 4.43 & 9.62 \\
\hline 1975 & 0.84 & 10.93 & 3.72 & -5.56 & 5.29 & -7.76 & 11.77 & 2.70 & 12.66 & 22.46 \\
\hline 1976 & 13.31 & 0.40 & 16.63 & 21.49 & -8.14 & -7.39 & 17.57 & -17.41 & 13.65 & 12.22 \\
\hline 1977 & 8.30 & -12.20 & 24.24 & 7.83 & -11.56 & -1.22 & -1.09 & 21.67 & -11.56 & -28.87 \\
\hline 1978 & 24.03 & 30.03 & 27.36 & 20.89 & 35.59 & 75.50 & -4.66 & 3.37 & 9.90 & 15.73 \\
\hline 1979 & 36.33 & 43.85 & 42.07 & 39.54 & 47.79 & 20.20 & -3.76 & 25.09 & 19.15 & 32.80 \\
\hline 1980 & 34.57 & 53.17 & 71.83 & 93.64 & 54.08 & 108.94 & 9.13 & 4.94 & -49.76 & -13.31 \\
\hline 1981 & 22.06 & 29.37 & 26.51 & 45.68 & 23.72 & 11.95 & -6.39 & 53.31 & 13.38 & 4.52 \\
\hline 1982 & -2.32 & -24.65 & 3.20 & -10.20 & -41.09 & -36.90 & -24.02 & -17.32 & -23.26 & -44.85 \\
\hline 1983 & 1.08 & -32.70 & 2.77 & 18.15 & -42.08 & -35.22 & -8.72 & -53.84 & -13.70 & -22.29 \\
\hline 1984 & 11.24 & 19.14 & 6.12 & 8.56 & 28.79 & 9.35 & 3.73 & -11.54 & 16.38 & 28.67 \\
\hline 1985 & -8.42 & 0.89 & -12.34 & 65.95 & 14.94 & -12.68 & -0.87 & -1.65 & -14.11 & 1.36 \\
\hline 1986 & -23.07 & -14.28 & -27.52 & -35.28 & -15.24 & -23.41 & -1.28 & -8.72 & -1.71 & -5.30 \\
\hline 1987 & 23.47 & 0.90 & 26.26 & 23.27 & 4.77 & -11.03 & -6.01 & 4.91 & -1.11 & -1.95 \\
\hline 1988 & 4.49 & 27.86 & 2.78 & 3.40 & 51.60 & 145.16 & -3.08 & 12.11 & 14.82 & 28.47 \\
\hline
\end{tabular}

FUENTE: Cuadro 8. 
$5 \%$. En cuanto a los PC en las transacciones fronterizas se observan unos porcentajes negativos en los ingresos PC de esta variable, que sólo se corrige hasta en 1988 con un aumento de $15 \%$. En los egresos PC de las transacciones fronterizas hay una caída del $-49 \%$ en 1982 y un porcentaje positivo de $28 \%$ en 1988.

d) Desde 1982 la dinámica del sector externo en México y de Baja California ha cambiado, pero de manera muy diferente. En el plano nacional, desde 1982 se ha logrado una relativa estabilidad en los indicadores PC del sector externo; lo que no sucedió en la entidad.

Insistimos en que es en las exportaciones manufactureras PC en donde se han realizado los cambios más importantes a nivel nacional. Las importaciones totales PC de México han crecido a un ritmo más rápido que las de la entidad, aunque éstas aún siguen siendo más o menos el doble de aquéllas en términos absolutos.

\section{SECTOR EXTERNO: PIB E IPC}

Desde los affos treinta, la dinámica de la frontera norte de México ha estado vinculada a la economía exterior y al grado de su apertura; es en este marco que se ha construido en parte su aparato productivo y distributivo. El caso de Baja California es el más representativo de dicha situación, ya que su crecimiento se ha acompañado del régimen de zonas y perímetros libres desde hace tiempo.?

En Baja California la disponibilidad de la moneda internacional dominante, el dólar, es importante no sólo en cuanto a su uso como moneda internacional para inversiones productivas y comerciales, también es una moneda de circulación que funciona como medio de pago para el consumo individual (y en ciertos sectores de la sociedad es la forma de ingresos) de la población.

Por eso las devaluaciones tienen un impacto "especial" en la frontera norte: los cambios de valor del peso respecto al dólar afectan al conjunto de las actividades económicas de las empresas y al poder de compra de las

9 "La prolongada existencia de las zonas y perímetros libres y la continua y extensiva aplicación de políticas especiales para la frontera, implementadas por el gobiemo mexicano desde los años sesenta a través de diferentes programas fronterizos, ha diferenciado el desarrollo fronterizo del resto del país. El desarrollo de los estados del norte y la franja fronteriza ha seguido un patrón de crecimiento más homogéneo en comparación a otras regiones de México. Otras experiencias regionales comparables, que han sido objeto de una participación mayor de la intervención del estado, lo fueron el desarrollo de las cuencas hidrológicas en México y los considerables efectos negativos del impacto regional de la explotación petrolera en la región de las costas del golfo de México." (Castillo, 1986: 9). 
familias fronterizas de una manera directa a través de las importaciones cotidianas que éstas hacen desde el mercado norteamericano.

En efecto, bajo estas consideraciones se puede decir que "La crisis en la frontera no puede entenderse plenamente sin aproximarnos previamente, así sea en sus líneas generales, a la crisis económica nacional. Aquélla es un reflejo frecuentemente ampliado, del agotamiento del modelo de desarrollo económico de corte expansionista que se materializó en graves problemas en el sector externo de nuestra economía." (Tamayo, 1982: 154)

En los dos primeros apartados del presente trabajo se expuso brevemente la crisis estructural desde una visión de la dinámica del sector externo para el país y para Baja California. ${ }^{10}$ De cierta forma se acotó cómo los años de crisis fueron años de cambios bruscos en dicho sector, y se apuntaron además los ajustes sufridos en los indicadores del mismo.

El objetivo de esta última parte es presentar los resultados de un ejercicio estadístico (análisis de regresión múltiple lineal) donde las variables dependientes son el PIB (producto interno bruto) por un lado, $y$ por el otro el IPC (ingresos per cápitas) exclusivamente para Baja California. Las variables independientes son las exportaciones, importaciones y los ingresos y egresos de las transacciones fronterizas de la entidad para el período de 1970 a 1988.

El objetivo de este ejercicio es ponderar y evaluar adecuadamente el peso y la importancia del sector externo para el crecimiento económico (PIB) y para el ingreso per cápita de la entidad. Se trabajaron, en el análisis de regresión, tres medidas para las variables independientes: en términos absolutos, según el índice de crecimiento base $1970=100$ y según el porcentaje de crecimiento anual. Posteriormente se estableció una media aritmética para ellas. Es a ésta a la que le daremos mayor atención.

Recuerden que los coeficientes de regresión de las variables independientes -que en este caso se exponen en porcentajes - miden la cantidad en que aumenta o disminuye (según el signo "+"o "-") la variable dependiente cuando la independiente aumenta una unidad. Es decir, miden la elasticidad de la variable dependiente respecto a la independiente.

Hablamos aquí en general del sector externo en referencia a la balanza comercial y de la variable transacciones fronterizas exclusivamente, aunque sería interesante analizar posteriormente otras.

\footnotetext{
${ }^{10} \mathrm{Al}$ respecto, se hacen dos afirmaciones: que las crisis en la frontera norte están sumamente ligadas a las devaluaciones. Y que "la política devaluatoria se ha encaminado a modificar el patrón tradicional de consumo fronterizo en favor del empresario nacional al impedir, mediante la restricción del poder adquisitivo, el acceso de la población asalariada a las importaciones" (Moctezuma y Mungaray, 1985: 27). Estamos de acuerdo con la primera, pero no con la segunda afimación: las devaluaciones obedecen a situaciones nacionales.
} 
Los resultados de este ejercicio se presentan en el cuadro 9 para el PIB y en el cuadro 10 para IPC. Los coeficientes de determinación - que explica en porcentaje el modelo usado, o sea las variaciones del PIB y del IPC, por las variables independientes - fueron 0.61 para el PIB y 0.75 para el IPC. Por tanto, el modelo no fue muy bueno para el primero, regular para el segundo. Estudiando ahora el coeficiente de correlación — que mide la fuerza o grado del modelo lineal - los resultados son 0.78 para el PIB y 0.87 para el IPC.

Por lo tanto, una primera conclusión es que el IPC se encuentra en una mayor medida "determinado" por el sector externo que el PIB. Es decir, el nivel de bienestar social en la entidad se encuentra frente a un condicionamiento considerable por el sector externo.

En cl análisis de regresión del PIB con el sector externo resaltan los siguientes resultados:

1) la variable más fuertemente relacionada al crecimiento económico fue la de las importaciones, con una media de $48 \%$. Esto es debido a que en los años de crecimiento económico se requieren mayores importaciones para satisfacer la demanda incrementada de las empresas y de la población, tal como se vio en la primera parte del trabajo; dada la insuficiencia productiva y de oferta que sufre el aparato productivo local.

2) La que menos contribuye al crecimiento económico son los ingresosen las transacciones fronterizas, con una media de $22 \%$. Estos ingresos parecen incrementarse en la medida en que cambia el valor del peso respecto al dólar, pero con muy poca probabilidad de ubicarse definitivamente en el mercado local.

3) Parece que las exportaciones así como los egresos en las transacciones fronterizas tienen el efecto de frenar débilmente el crecimiento del PIB. Quizá las exportaciones no coadyuven adecuadamente a una redistribución de las divisas generadas hacia otros sectores económicos y además, como ya también se anotó, las exportaciones tienden a crecer cuando la economía se encuentra en recesión o crisis. En cuanto a la poca relación entre los egresos fronterizos y el crecimiento económico quizá se deba a que los egresos son en fin de cuentas una forma de "exportación" de divisas no estacionadas en la entidad.

Segunda conclusión: el análisis refleja que el crecimiento económico requiere fuertes importaciones. Que los ingresos fronterizos crecen cuando la economía de la entidad se encuentra en recesión o en crisis. Además las exportaciones no parecen surtir ningún efecto multiplicador en el crecimiento económico de Baja California. Estas situaciones representan uno de los peores círculos viciosos de la economía fronteriza.

En el análisis de segresión del IPC con el sector externo resaltan los siguientes resultados: 1) Son las variables de egresos en las transacciones fronterizas y en las importaciones, las que más determinan la elasticidad 
CUADRO 9. Análisis de regresión en la determinación del producto interno bruto de Baja California según variables seleccionadas del sector externo de 1970 a 1988.

\begin{tabular}{lcccc}
\hline Medida: & $\begin{array}{c}\text { En términos } \\
\text { absolutos }\end{array}$ & $\begin{array}{c}\text { Según índice } \\
\text { de crec. } \\
\text { base } 1970=100\end{array}$ & $\begin{array}{c}\text { Según porcent. } \\
\text { de crecimiento } \\
\text { anual }\end{array}$ & $\begin{array}{c}\text { Media } \\
\text { arit. }\end{array}$ \\
\hline
\end{tabular}

Coeficiente de correlación

0.81

0.81

0.73

0.78

Coeficientes de regresión de las variables independientes: (en \%)

$\begin{array}{lrrrr}\text { Exportaciones } & 2.07 & 2.43 & -24.93 & -6.81 \\ \text { Importaciones } & 54.02 & 54.67 & 36.04 & 48.24 \\ \begin{array}{l}\text { Ingresos en } \\ \text { trans. front. }\end{array} & -42.38 & -41.87 & 17.42 & -22.28 \\ \begin{array}{l}\text { Egresos en } \\ \text { trans. front. }\end{array} & -1.53 & -1.03 & -26.61 & -9.72\end{array}$

FUENTE: Cuadros 1,5 y 7.

NOTA: El total no da $100 \%$ porque los valores "reales" de los coeficientes de regresión se ponderaron en función del "peso" o importancia de cada una de ellas frente a la variable dependiente PIB y según su elasticidad, ya sea positiva (+) o negativa (-).

CUADRO 10. Análisis de regresión en la determinación del ingreso per cápita de Baja California según variables seleccionadas del sector externo de 1970 a 1988.

\begin{tabular}{lcccc}
\hline Medida: & $\begin{array}{c}\text { En términos } \\
\text { absolutos }\end{array}$ & $\begin{array}{c}\text { Según índice } \\
\text { de crec. } \\
\text { base } 1970=100\end{array}$ & $\begin{array}{c}\text { Según porcent. } \\
\text { de crecimiento } \\
\text { anual }\end{array}$ & $\begin{array}{c}\text { Media } \\
\text { arit. }\end{array}$ \\
\hline
\end{tabular}

Coeficientes

$\begin{array}{lllll}\text { de correlación } & 0.85 & 0.90 & 0.84 & 0.87\end{array}$

Coeficientes de regresión de las variables independientes: (en \%)

$\begin{array}{lrrrr}\text { Exportaciones } & -0.04 & -34.24 & -1.84 & -12.04 \\ \text { Importaciones } & 29.78 & 20.63 & 20.79 & 23.74 \\ \begin{array}{l}\text { Ingresos en } \\ \text { trans. front. }\end{array} & 10.38 & 16.22 & -29.99 & -1.13 \\ \begin{array}{l}\text { Egresos en } \\ \text { trans. front. }\end{array} & 59.80 & 28.90 & 47.37 & 45.36\end{array}$

FUENTE: Cuadros 2,5 y 7.

El total no da $100 \%$ porque los valores "reales" de los coeficientes de regresión se ponderaron en función del "peso" o importancia de cada una de ellas frente a la variable dependiente PIB y según su elasticidad, ya sea positiva (+) o negativa (-). 
positiva del IPC; 45 y $28 \%$ respectivamente. 2) Las exportaciones parecen surtir un efecto ligeramente negativo en el IPC; este efecto es menor para los ingresos de las transacciones fronterizas.

Tercera conclusión: el IPC de la entidad parece estar más relacionado con las importaciones y con los egresos fronterizos que con las exportaciones o los ingresos fronterizos. Esta situación se explica porque en una cierta medida los niveles del IPC siguen en función de la capacidad de la sociedad bajacaliforniana de interactuar con la economía norteamericana en términos de capacidad de compra con divisas. Es decir, un porcentaje importante del bienestar de la población está en función de la capacidad de compra dolarizada de la economía y de la población bajacaliforniana.

En resumen, el crecimiento económico así como el aumento del bienestar de la población de B. C. se ubican, hablando del papel del sector externo, en sus relaciones con la economía exterior en términos de una balanza deficitaria.

\section{CONCLUSIONES}

La dinámica del sector externo de México se encuentra delimitado por el comportamiento de la economía nacional; los ciclos de ésta están claramente expresados en el comportamiento de aquél. Baja California tiene una dinámica del sector externo diferente al del país: una incapacidad crónica en las exportaciones y una fuerte elasticidad de aumentar las importaciones. Desde 1982, el problema de la balanza de pagos en México se encuentra en la variable "otros" y no en la balanza comercial.

Los per cápita del comercio exterior confirman la idea anterior: en la entidad, a pesar de los problemas económicos que implica la situación nacional, los PC son elevados en las importaciones y bajos en las exportaciones. Aquéllas son un elemento fundamental para las actividades económicas de la región y son también una parte importante del consumo fronterizo.

La determinación mayor del comercio exterior en el IPC que en el crecimiento del PIB de la entidad señala una característica fronteriza: los niveles de bienestar social de la población se encuentran relacionados con la dinámica del sector externo fronterizo.

De ahí que sea necesario replantear el papel del sector externo en la frontera norte de México, pues ya no es posible que la dinámica de crecimiento del PIB de la economía y el crecimiento del IPC de la población fronteriza dependan en alto nivel de las importaciones y de los ingresos fronterizos - para el PIB - y los egresos - para IPC - sin crear fuertes déficits en nuestras relaciones con la economía internacional. 
Por eso la urgencia de encontrar otras fórmulas en la dinámica del sector externo: éste debe de impulsar el crecimiento económico y favorecer el bienestar de la población; el crecimiento de las exportaciones no tiene por qué darse en condiciones de recesión económica ni debe de implicar una dinámica regresiva en el bienestar de la población, como ha sucedido principalmente desde 1982 hasta nuestros días.

\section{BIBLIOGRAFÍA}

CALZADA Falcón, Fernando. 1986. "Algunos aspectos del comercio exterior de México". Investigación Económica. Vol. XLV, no. 177, julio-septiembre de 1986. Facultad de Economía UNAM.

CASTILLO, Víctor M. 1986. "Desarrollo regional y frontera norte. Configuración regional: 1960-1980.” Cuadernos de Economía. Serie 2, no. 1. Escucla de Economía UABC.

CORDERA C., Rolando y Clemente Ruíz D. 1980. "Esquema de periodización del desarrollo capitalista en México. Notas." Investigación Econbmica. Vol. XXXIX, no. 153, julio-septiembre de 1980. Facultad de Economía UNAM.

LÓPEZ G., Julio. 1983. "La economía mexicana: cvolución reciente, perspectivas y alternativas." Investigación Economica. Vol. XLII, no. 164, abril-julio de 1983. Facultad de Economía UNAM.

MOCTEZUMA M., Patricia y Alejandro Mungaray L. 1985. "Ganancias, devaluaciones y salarios en la frontera norte." Economía Informa. No. 124, enero de 1985. Facultad de Economía UNAM.

RIVERA Ríos, Miguel Ángel. 1986. Crisis y reorganización del capitalismo mexicano: 1960-1985. Ediciones ERA. Colección: Problemas de México. México.

SÁNDEZ Pérez, Agustín. 1987. "Estructura y Dinámica del sector manufacturero bajacaliforniano: 1960-1985. Cuadernos de Ciencias Sociales. Serie 3, no. 7. Instituto de Investigaciones Sociales UABC.

TAMAYO, Jesús. 1982. "La frontera norte de México y la crisis de 1982: algunos comentarios preliminares." Estudios Fronterizos. Año 1, no. 1, mayo-agosto de 1983. Instituto de Investigaciones Sociales UABC.

VALENZUELA Feijoó, José. 1986. El capitalismo mexicano en los ochentas. Ediciones ERA. Colección: Problemas de México. México. 